\title{
The vertical variation of the redox state of the Hainan lithospheric mantle: constraint from peridotite xenoliths
}

\author{
JiANG YU ${ }^{1}$, YAN-TAO HAO*1, PEI LI ${ }^{1}$, QUN-KE XIA ${ }^{1}$
}

${ }^{1}$ Key Laboratory of Geoscience Big Data and Deep Resource of Zhejiang Province, School of Earth Sciences, Zhejiang University ythao@zju.edu.cn

The oxygen fugacity can influence physical properities of the mantle, such as mantle solidus, electronic conducivity, also control the chemical specitation of the volatiles (C_H_S)-bearing fluids/melts. Although it is generally held that the upper mantle became more reduced with the depth, the redox state of the mantle, especially the outermost part lithosphere, can be locally and signifcantly affected by mantle processes which, however, are still poor understood. In this study, the combined investigation of major, trace element concentrations and the water contents on a suit of peridotite xenoliths hosted by the Cenozoic basalts from the Hainan island, China were taken to explore the vertical variation of the mantle redox state and the related processes. The spinel peridotite xenoliths were indicated to undergo less than $18 \%$ degrees of partial melting and various extents of the mantle metasomatism by the major element concntration of minerals and trace element patterns of cpx $(\mathrm{La} / \mathrm{Ybn}>1)$, respectivley. The oxygen fugacity of the Hainan peridotites, calculated on oxygen thermobarometry, falls betweeen $\triangle \mathrm{FMQ}-2.95$ and $+0.21 \log$ units, within the range reported for the continental mantle. The redox state of the peridotites, in term of both of oxgen fugacity and the ratio of $\mathrm{Fe}^{3+} /$ Fetotal in the spinel, show the positive correlations with the temperature that reflects the depth from which the mantle pieces came. This positive correlation contradicts with the common view that the oxygen fugacity decreases with the depth. Although the water contents show no correlation with the melting or metasomtism indexes (e.g. $\mathrm{Mg} \#$ of olivine, $\mathrm{Na}_{2} \mathrm{O}, \mathrm{La} / \mathrm{Ybn}$ of $\mathrm{cpx}$ ), the water-rich samples are those with high oxygen fugacity. The observation can be explained by the interaction of the lithospheric mantle column with an upwelling water-rich and oxidized melt/fluids of deep origin. The finding also indicate that small volume melt/fluid from the deep lithospheric mantle can be exhausted during its ascent without obvious petrological or geochemical evidence. 